\title{
Graphical and queuing model of banking operations in Intercontinental Bank PIc, Nigeria
}

\author{
Hycinth Chukwudi Iwu', Chukwudi Justin Ogbonna ${ }^{1}$, Opara Jude ${ }^{2}$ \\ ${ }^{1}$ Federal University of Technology Owerri Nigeria, Owerri Nigeria \\ ${ }^{2}$ Department of Statistics, Imo State University, Owerri Nigeria
}

Email address:

iwuchuk@yahoo.com (H. C. Iwu),d_ogbonna59@yahoo.com (C. J. Ogbonna),judend88@yahoo.com (O. Jude)

\section{To cite this article:}

Hycinth Chukwudi Iwu, Chukwudi Justin Ogbonna, Opara Jude. Graphical and Queuing Model of Banking Operations in Intercontinental Bank Plc, Nigeria. American Journal of Theoretical and Applied Statistics. Vol. 2, No. 6, 2013, pp. $282-292$. doi: $10.11648 /$ j.ajtas.20130206.27

\begin{abstract}
This study is aimed at modeling the influence and network relationship existing amongst members of staff of commercial banks. It also solved the problem of profit maximization through staff reduction in a commercial banking system. In this paper, graph and queuing theories were applied in achieving the smooth running of the operations in a commercial bank using Intercontinental bank plc as a case study.
\end{abstract}

Keywords: Graph Theory, Queuing Theory, Banking Operations, Queue Discipline, Arrival Pattern

\section{Introduction}

The origin of graph theory dates back to 1736 the time of the Swiss mathematician Leonhard Euler. As a resident of Konigsberg, Germany, Euler wondered if it was possible to cross the city's network of seven bridges only once during a walk across town. He mathematically transformed his question and took the essential elements of the situation and represented then in a graph using lines and points. His graph proved that if there are more than two points with anodd number of lines to or from the points, it was not possible to cross all the seven bridges first once. Euler published his findings in 1736 in what many consider to be the fist documented use of graph theory. Despite this start, more than 260 years ago, graph theory was not truly studied or utilized until recently.

There are descriptions of graph problems back in the middle ages, it was in the past 30 or 50 years that graph became a real discipline in mathematics and other fields. With a graph, researches can state complex problems rather easily and then study the properties of the model independent of the source.

The application of graph theory as can be seen in many discipline helps in studying and researching in science. The chip-design especially for very large micro-processors would not be possible without graph theory. The microprocessor will in turn power a computer to process large problems in graph theory. It is widely accepted that computer science and graph theory complement each other.

The World Wide Web can be modeled as a directed graph where each node is a web page and each hyperlink is an edge or line. Studying web graph gives an insight into lots of things such as web algorithm for crawling, searching or ranking web resources. Graph theory can be used to see how a computer virus would travel through the web. The internet is a large graph and if one wants to isolate certain cyber attacks, one can do it using graph theory.

A communications network can be modeled as a graph with vertices representing the nodes and with directed edges representing direct two way communication link between the nodes. In order that all pairs of nodes are in communication, the graph however must be connected.

In civil engineering, a road network in which at least some of the roads are one-way can be modeled by a directed graph. The nodes are road junctures, each two way road is represented by a pair of arcs one in each direction, loops are allowed and they may represent "circles" that occur in housing developments and in industrial parks.

Graphs are natural mathematical models of physical situations which the points represent either objects or locations and the lines represent connections.

\subsection{Statement of Problem}

Despite the numerous staff in commercial banks, 
customers of these banks do not receive a first class service due to the poor network relationship existing amongst members of staff of the commercial banks. Hence, this study is aimed at modeling the influence and network relationship existing amongst members of staff of commercial banks using Intercontinental bank plc as a case study. It also seeks to use the application of graph theory in solving problems such as profit maximization through staff reduction in a commercial banking system.

The major objectives of this study include;

- Evaluating the quality of services provided to the customers of intercontinental bank plc by the different operational units in the bank.

- Analysis of the network relationship existing amongst members of staff of intercontinental bank plc.

- $\quad$ Profit maximization by staff reduction.

\subsection{Related Literature Review}

Graph and queuing theory have being used by so many authors for modeling and data analysis which yielded useful results.

Gustav Kirchhoff (1824-1887) employed the concept of graph theory in the calculation of currents in electrical network of circuits.

Arthur Cayley (1821-1895) used the concept of graph theory in the study of chemical molecules.

Thomas P Kirkman (1806-1895) and William R Hamilton (1805-1865) postulated the Hamilton graph using the concept of graph theory.

A.K Erlang (1940) used queuing theory to study data over telephone networks.

Leonard Kleinrock (1950) used queuing theory in the study of internet to determine the number of servers and the size of the data packets required to make the systems work for everyday use.

However, this paper is aimed at considering the different operations of Intercontinental bank plc without loss of generality, using the set of observations to extract and predict the smooth running of these operations even with a reduction in the number of staff.

\section{Materials and Methods}

The data used in this study was obtained from Intercontinental bank plc. It gives a detailed break down of the various units operating in a commercial bank system. It also gives a graphical representation of the network relationship existing amongst members of staff in a commercial bank and a mathematical analysis of these data using matrices.

\subsection{Definition of Terms}

The following terms have to be explained for the clear understanding of this work;

- Graph: this is a diagram consisting of points called vertices joined together by lines called edges; each edge joins exactly two vertices.

- $\quad$ A directed graph: a directed graph $\mathrm{G}=(\mathrm{V}, \mathrm{A}, 0)$ consists of a set $\mathrm{V}$ whose elements are called vertices, a set $\mathrm{E}$ whose elements are called edges or arcs, an incidence function $\phi: \mathrm{A} \rightarrow \mathrm{V} \times \mathrm{V}$ which assigns each edge a tail and a head, an arc form a vertex into itself which is called a loop.

- $\quad$ Undirected graph: an undirected graph $\overline{\mathrm{G}}=(\mathrm{V}, \mathrm{E}, \theta)$ consists of a set $\mathrm{V}$ of vertices, a set $\mathrm{E}$ of edges and a function $\theta$ which maps an edge a $\varepsilon$ E into an unordered pair (p, q) and (q, p) of vertices called its ends.

- Isomorphism of graphs: two graphs are said to be isomorphic if there is one-to -one correspondence between their vertices and between their edges such that their incidences are preserved.

- Degree of a vertex: This is the number of edges incident with the vertices and it's denoted by deg (v).

- Walk: A walk in a graph is an alternating sequence of vertices and edges.

- In-degree of a vertex: in a graph with directed edges, the in-degree of a vertex $\mathrm{V}$ is the number of edges with $\mathrm{V}$ as their terminal vertex.

- Out-degree of vertex: This is the number of edges with $\mathrm{V}$ as their initial vertex.

- Adjacency matrix: this is an $n \times n$ zero-one matrix with 1 as its ( $i, j$ )th entry when vertex $V_{i}$ and $V_{j}$ are adjacent and 0 as its $(i, j)$ th entry when they are not adjacent.

- An edge: this is simply the line joining two vertices.

\subsection{Network Relationship amongst Intercontinental Bank Staff}

Intercontinental bank is a merger of 4 banks namely; Intercontinental Bank, Gateway Bank, Equity Bank and Global Bank. Since these four banks were merged, there has been need to define the number of staff required to run a branch.

A branch of intercontinental bank is divided into four units namely;

- Operations unit

- $\quad$ Retail and personal banking unit.

- $\quad$ Oil and Gas unit

- Electronic Banking unit (e- banking).

\subsubsection{The Operations Unit}

This unit is made up of the front tellers who are responsible for cash payment and withdrawal from the customers. The funds transfer unit responsible for the transfer of funds from one account to the other or from one branch to the other. This may be affected either electronically or by mail. In addition to this, the funds transfer unit is also responsible for the remittance of fund from one bank to the other either locally or internationally and the issuance of manager's cheques. The customer care unit is responsible for account opening and closing, balance inquiry and account statement, cheque confirmation. The 
merchant tellers confirm cash paid into the customers account and post customers transaction. The bulk tellers handle the cash paid in by a customer. The operations unit is headed by a cash officer who is responsible for the control and administration of policies that apply to vault opening, managing cash and teller areas, authorization of transactions and security. The cash officer reports only to the operations manager who oversees all matters affecting operations of the bank. From the information gathered from the bank, it was observed that the cash officer has direct access to all the systems in the operations unit except that of the operations manager and thus acts in the capacity of the operations manager in her absence.

\subsubsection{Electronic and Consumer Banking Unit}

This unit deals with all electronic banking transactions. They include; bank debit, credit card issuance and usage monitoring, mobile and internet banking. This unit is headed by a relationship manager who may have about six relationship officers responsible for marketing of these products.

A branch of intercontinental bank is headed by a branch head who oversees the smooth running of all the banking operations. He has direct access to all the branch staff and can influence them in turn.

\subsubsection{Analysis of Data}

From the information acquired from the bank, it was observed that the branch head has direct influence one all the unit heads. The unit heads in turn have direct influence on the staff directly under them and thus making the branch head have influence on them.

We also note that the unit heads do not influence one another. The branch resident controller does not get influenced by any member of staff and for the purpose of this study would be called the isolated node.

The graph below shows the network relationship and influence existing amongst members of staff of a branch of intercontinental bank.

$$
\text { Key }
$$

$$
\mathrm{B}=\text { BRANCH HEAD }
$$$$
\text { BOM }=\text { BRANCH OPERATIONS MANAGER }
$$$$
\mathrm{COF}=\mathrm{CASH} \text { OFFICER }
$$$$
\mathrm{BRC}=\text { BRANCH RESIDENT CONTROLLER }
$$$$
\mathrm{CSO}=\text { CUSTOMER SERVICE OFFICER }
$$$$
\mathrm{M}=\text { MERCHANT TELLER }
$$

FTO $=$ FUNDS TRANSFER OFFICER

$$
\mathrm{T}=\text { TELLER (FRONT DESK) }
$$

$$
\mathrm{BT}=\mathrm{BULK} \text { TELLER }
$$

RM $($ R\&P) $=$ RELATIONSHIP MANGER $($ RETAIL \& PERSONAL)

RO $($ R\&P) $=$ RELATIONSHIP OFFICER (RETAIL \& PERSONAL)

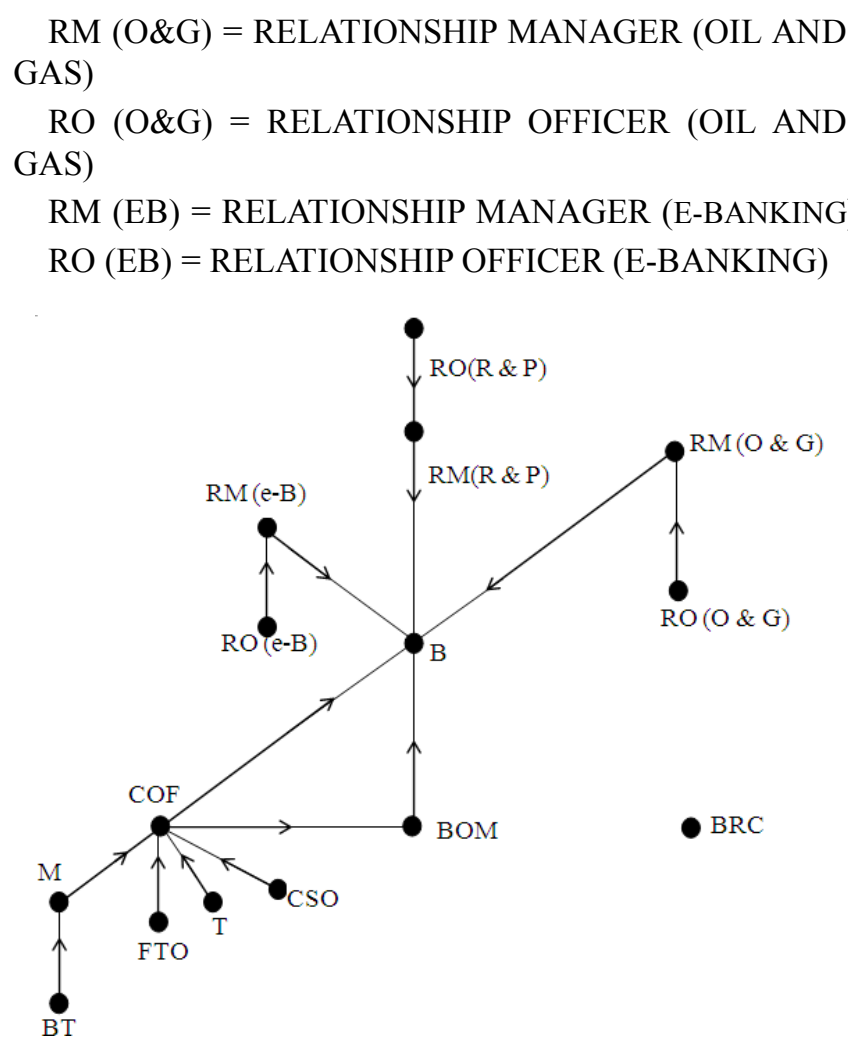

Fig 1. A Graph Showing the Network Relationship amongst Members of Staff of Intercontinental Bank Plc.

\subsubsection{Mathematical Analysis}

The mathematical analysis will be done using matrices which provide an easy way of describing graphs. Matrices also lend themselves well to computer manipulations since it is easier to use computer for an extensive computational work in graph theory. To represent the network relationship graph in a matrices, we use a $15 \times 15$ matrix whose entries are 0 's and 1's, where 1 is used when there is a direct influence of the activities of one member of staff by another and 0 is used when there is no direct influence of the activities of a staff by another. We redefine the terms as follows;

$$
\begin{array}{lll}
\mathrm{B}=\mathrm{V}_{1}, & \mathrm{~T}=\mathrm{V}_{8} \\
\mathrm{BOM}=\mathrm{V}_{2}, & \mathrm{BT}=\mathrm{V}_{9} \\
\text { COF }=\mathrm{V}_{3}, & \text { RM }(\mathrm{R} \& \mathrm{P})=\mathrm{V}_{10} & \\
\mathrm{BRC}=\mathrm{V}_{4}, & \text { RM }(\text { O\&G })=\mathrm{V}_{11} & \\
\mathrm{CSO}=\mathrm{V}_{5}, & \mathrm{RM}(\mathrm{e}-\mathrm{B})=\mathrm{V}_{12} \\
\mathrm{M}=\mathrm{V}_{6}, & \text { RO (R\&P) }=\mathrm{V}_{13} & \\
\mathrm{FTO}=\mathrm{V}_{7}, & \text { RO (O\&G) }=\mathrm{V}_{14} & \text { RO (e-B) }=\mathrm{V}_{15}
\end{array}
$$

Below is the matrix showing the direct influence of the activities of one member of staff of intercontinental bank plc by another. Note that an $\mathrm{n} \times \mathrm{n}$ matrix will be used to represent the network relationship graph because it is conformable and can be inverted. 


\begin{tabular}{|c|c|c|c|c|c|c|c|c|c|c|c|c|c|c|c|}
\hline $\mathrm{V}_{1}$ & $V_{2}$ & $V_{3}$ & $V_{4}$ & $V_{5}$ & $V_{6}$ & $V_{7}$ & $V_{8}$ & $\mathrm{~V}_{9}$ & $V_{10}$ & $\mathrm{~V}_{11}$ & $V_{12}$ & $V_{13}$ & $V_{14}$ & $\mathrm{~V}_{15}$ & \\
\hline 0 & 1 & 1 & 0 & 0 & 0 & 0 & 0 & 0 & 1 & 1 & 1 & 0 & 0 & 0 & $\mathrm{~V}_{1}$ \\
\hline 0 & 0 & 1 & 0 & 0 & 0 & 0 & 0 & 0 & 0 & 0 & 0 & 0 & 0 & 0 & $V_{2}$ \\
\hline 0 & 0 & 0 & 0 & 1 & 1 & 1 & 1 & 0 & 0 & 0 & 0 & 0 & 0 & 0 & $V_{3}$ \\
\hline 0 & 0 & 0 & 0 & 0 & 0 & 0 & 0 & 0 & 0 & 0 & 0 & 0 & 0 & 0 & $\mathrm{~V}_{4}$ \\
\hline 0 & 0 & 0 & 0 & 0 & 0 & 0 & 0 & 0 & 0 & 0 & 0 & 0 & 0 & 0 & $V_{5}$ \\
\hline 0 & 0 & 0 & 0 & 0 & 0 & 0 & 0 & 1 & 0 & 0 & 0 & 0 & 0 & 0 & $\mathrm{~V}_{6}$ \\
\hline 0 & 0 & 0 & 0 & 0 & 0 & 0 & 0 & 0 & 0 & 0 & 0 & 0 & 0 & 0 & $V_{7}$ \\
\hline 0 & 0 & 0 & 0 & 0 & 0 & 0 & 0 & 0 & 0 & 0 & 0 & 0 & 0 & 0 & $\mathrm{~V}_{8}$ \\
\hline 0 & 0 & 0 & 0 & 0 & 0 & 0 & 0 & 0 & 0 & 0 & 0 & 0 & 0 & 0 & $\mathrm{~V}_{9}$ \\
\hline 0 & 0 & 0 & 0 & 0 & 0 & 0 & 0 & 0 & 0 & 0 & 0 & 1 & 0 & 0 & $V_{10}$ \\
\hline 0 & 0 & 0 & 0 & 0 & 0 & 0 & 0 & 0 & 0 & 0 & 0 & 0 & 1 & 0 & $\mathrm{~V}_{11}$ \\
\hline 0 & 0 & 0 & 0 & 0 & 0 & 0 & 0 & 0 & 0 & 0 & 0 & 0 & 0 & 1 & $V_{12}$ \\
\hline 0 & 0 & 0 & 0 & 0 & 0 & 0 & 0 & 0 & 0 & 0 & 0 & 0 & 0 & 0 & $\mathrm{~V}_{13}$ \\
\hline 0 & 0 & 0 & 0 & 0 & 0 & 0 & 0 & 0 & 0 & 0 & 0 & 0 & 0 & 0 & $V_{14}$ \\
\hline 0 & 0 & 0 & 0 & 0 & 0 & 0 & 0 & 0 & 0 & 0 & 0 & 0 & 0 & 0 & $\mathrm{~V}_{15}$ \\
\hline
\end{tabular}

\subsubsection{Deductions from Graph}

1. The following members of staff are not influenced by other members of staff,

- The Branch head

- The Branch resident controller

Also notice that the branch resident controller does not influence the activities of anyone either.

2. Each edge appears once in a matrix, so the sum of all elements of the matrix equals the number of edges of the graph. In figure 1, the number of edges in the graph is 14 which correspond to the sum of the entire element in the matrix.

3. The various degrees of the vertices in the graph are
$\operatorname{Deg}\left(\mathrm{V}_{1}\right)=5$
$\operatorname{Deg}\left(\mathrm{V}_{5}\right)=1$
$\operatorname{Deg}\left(\mathrm{V}_{7}\right)=1$
$\operatorname{Deg}\left(\mathrm{V}_{2}\right)=2$
$\operatorname{Deg}\left(\mathrm{V}_{6}\right)=1$
$\operatorname{Deg}\left(\mathrm{V}_{3}\right)=6$
$\operatorname{Deg}\left(\mathrm{V}_{11}\right)=2$
$\operatorname{Deg}\left(\mathrm{V}_{8}\right)=1$
$\operatorname{Deg}\left(\mathrm{V}_{13}\right)=1$

$$
\begin{array}{lll}
\operatorname{Deg}\left(\mathrm{V}_{4}\right)=0 & \operatorname{Deg}\left(\mathrm{V}_{12}\right)=2 & \operatorname{Deg}\left(\mathrm{V}_{14}\right)=1 \\
\operatorname{Deg}\left(\mathrm{V}_{9}\right)=2 & & \operatorname{Deg}\left(\mathrm{V}_{15}\right)=1 \\
\operatorname{Deg}\left(\mathrm{V}_{10}\right)=2 & &
\end{array}
$$

See that the sum of the degree of the graph equals twice the number of edges in the graph i.e.

$\sum \operatorname{deg}(\mathrm{v})=5+2+6+0+1+1+1+1+2+2+2+2$ $+1+1+1=28 \mathrm{veV}$ and the total number of edges in the graph is 14 i.e. $2 \mathrm{x}$ the number of edges $=2 \times 14=28$ this satisfies the Hand shaking theorem that states that the total degree of any graph equals twice the number of edges in the graph. Also notice that the total degree of the graph is even i.e. 28 and the number of odd vertices is also even i.e. 8 and this satisfies the two corollaries associated with the handshaking theorem that states that the total degree of any graph has an even number of vertices of odd degree.

4. We go ahead to find the square of the matrix A representing the network relationship of graph.

\begin{tabular}{lllllllllllllllll}
\hline $\mathrm{V}_{1}$ & $\mathrm{~V}_{2}$ & $\mathrm{~V}_{3}$ & $\mathrm{~V}_{4}$ & $\mathrm{~V}_{5}$ & $\mathrm{~V}_{6}$ & $\mathrm{~V}_{7}$ & $\mathrm{~V}_{8}$ & $\mathrm{~V}_{9}$ & $\mathrm{~V}_{10}$ & $\mathrm{~V}_{11}$ & $\mathrm{~V}_{12}$ & $\mathrm{~V}_{13}$ & $\mathrm{~V}_{14}$ & $\mathrm{~V}_{15}$ \\
\hline 0 & 1 & 0 & 0 & 1 & 1 & 1 & 1 & 0 & 0, & 0 & 0 & 1 & 1 & 1 & $\mathrm{~V}_{1}$ \\
0 & 0 & 0 & 0 & 1 & 1 & 1 & 1 & 0 & 0 & 0 & 0 & 0 & 0 & 0 & $\mathrm{~V}_{2}$ \\
0 & 0 & 1 & 0 & 0 & 0 & 0 & 0 & 0 & 0 & 0 & 0 & 0 & 0 & 0 & $\mathrm{~V}_{3}$ \\
0 & 0 & 0 & 0 & 0 & 0 & 0 & 0 & 1 & 0 & 0 & 0 & 0 & 0 & 0 & $\mathrm{~V}_{4}$ \\
0 & 0 & 0 & 0 & 0 & 0 & 0 & 0 & 0 & 0 & 0 & 0 & 0 & 0 & 0 & $\mathrm{~V}_{5}$ \\
$\mathrm{~A}^{2}=$ & 0 & 0 & 0 & 0 & 0 & 0 & 0 & 0 & 0 & 0 & 0 & 0 & 0 & 0 & $\mathrm{~V}_{6}$ \\
0 & 0 & 0 & 0 & 0 & 0 & 0 & 0 & 0 & 0 & 0 & 0 & 0 & 0 & 0 & $\mathrm{~V}_{7}$ & 0 \\
0 & 0 & 0 & 0 & 0 & 0 & 0 & 0 & 0 & 0 & 0 & 0 & 0 & 0 & 0 & $\mathrm{~V}_{8}$ \\
0 & 0 & 0 & 0 & 0 & 0 & 0 & 0 & 0 & 0 & 0 & 0 & 0 & 0 & 0 & $\mathrm{~V}_{9}$ \\
0 & 0 & 0 & 0 & 0 & 0 & 0 & 0 & 0 & 0 & 0 & 0 & 0 & 0 & 0 & $\mathrm{~V}_{10}$ \\
0 & 0 & 0 & 0 & 0 & 0 & 0 & 0 & 0 & 0 & 0 & 0 & 0 & 0 & 0 & $\mathrm{~V}_{11}$ \\
0 & 0 & 0 & 0 & 0 & 0 & 0 & 0 & 0 & 0 & 0 & 0 & 0 & 0 & 0 & $\mathrm{~V}_{12}$ \\
0 & 0 & 0 & 0 & 0 & 0 & 0 & 0 & 0 & 0 & 0 & 0 & 0 & 0 & 0 & $\mathrm{~V}_{13}$ \\
0 & 0 & 0 & 0 & 0 & 0 & 0 & 0 & 0 & 0 & 0 & 0 & 0 & 0 & 0 & $\mathrm{~V}_{14}$ \\
0 & 0 & $\mathrm{a}$ & 0 & 0 & 0 & 0 & 0 & 0 & 0 & 0 & 0 & 0 & 0 & 0 & $\mathrm{~V}_{15}$ \\
\hline
\end{tabular}

From the matrix above, we see that the number of walks of length 2 from $V_{1}$ to $V_{15}$ is the $(1,15)$ th entry of $A^{2}$ and this is the entry 1 from the matrix. Also notice that from the graph, there is only one path of length 2 from $V_{1}$ to $V_{15}$ which is $\mathrm{B} \rightarrow \mathrm{RM}$ (e-Banking) $\rightarrow \mathrm{RO}$ (e-Banking).

The above deduction satisfies the theorem which states that let $\mathrm{G}$ be a graph with adjacency matrix $\mathrm{A}$ with respect to ordering $V_{1} V_{2} \ldots, V_{n}$ where the graph has either directed or undirected edges with multiple edges and loops. The number of different paths of length $r$ from $V_{i}$ to $V_{j}$ where $r$ is a positive integer equals the (i,j)th entry of $A^{r}$. We go ahead to compute $\mathrm{A}^{3}$ 


\begin{tabular}{cllllllllllllllll}
\hline $\mathrm{V}_{1}$ & $\mathrm{~V}_{2}$ & $\mathrm{~V}_{3}$ & $\mathrm{~V}_{4}$ & $\mathrm{~V}_{5}$ & $\mathrm{~V}_{6}$ & $\mathrm{~V}_{7}$ & $\mathrm{~V}_{8}$ & $\mathrm{~V}_{9}$ & $\mathrm{~V}_{10}$ & $\mathrm{~V}_{11}$ & $\mathrm{~V}_{12}$ & $\mathrm{~V}_{13}$ & $\mathrm{~V}_{14}$ & $\mathrm{~V}_{15}$ & 1 \\
\hline 0 & 0 & 0 & 0 & 1 & 1 & 1 & 1 & 1 & 0 & 0 & 0 & 1 & 1 & 1 & $\mathrm{~V}_{1}$ \\
0 & 0 & 0 & 0 & 0 & 0 & 0 & 0 & 0 & 0 & 0 & 0 & 0 & 0 & 0 & $\mathrm{~V}_{2}$ \\
0 & 0 & 1 & 0 & 0 & 0 & 0 & 0 & 0 & 0 & 0 & 0 & 0 & 0 & 0 & $\mathrm{~V}_{3}$ \\
0 & 0 & 0 & 0 & 0 & 0 & 0 & 0 & 0 & 0 & 0 & 0 & 0 & 0 & 0 & $\mathrm{~V}_{4}$ \\
0 & 0 & 0 & 0 & 0 & 0 & 0 & 0 & 0 & 0 & 0 & 0 & 0 & 0 & 0 & $\mathrm{~V}_{5}$ \\
$\mathrm{~A}^{3}=$ & 0 & 0 & 0 & 0 & 0 & 0 & 0 & 0 & 0 & 0 & 0 & 0 & 0 & 0 & $\mathrm{~V}_{6}$ \\
0 & 0 & 0 & 0 & 0 & 0 & 0 & 0 & 0 & 0 & 0 & 0 & 0 & 0 & 0 & $\mathrm{~V}_{7}$ \\
0 & 0 & 0 & 0 & 0 & 0 & 0 & 0 & 0 & 0 & 0 & 0 & 0 & 0 & 0 & $\mathrm{~V}_{8}$ & 0 \\
0 & $\mathrm{a}$ & 0 & 0 & 0 & 0 & 0 & 0 & 0 & 0 & 0 & 0 & 0 & 0 & 0 & $\mathrm{~V}_{9}$ \\
0 & 0 & 0 & 0 & 0 & 0 & 0 & 0 & 0 & 0 & 0 & 0 & 0 & 0 & 0 & $\mathrm{~V}_{10}$ \\
0 & 0 & 0 & 0 & 0 & 0 & 0 & 0 & 0 & 0 & 0 & 0 & 0 & 0 & 0 & $\mathrm{~V}_{11}$ \\
0 & 0 & 0 & 0 & 0 & 0 & 0 & 0 & 0 & 0 & 0 & 0 & 0 & 0 & 0 & $\mathrm{~V}_{12}$ \\
0 & 0 & 0 & 0 & 0 & 0 & 0 & 0 & 0 & 0 & 0 & 0 & 0 & 0 & 0 & $\mathrm{~V}_{13}$ \\
0 & 0 & 0 & 0 & 0 & 0 & 0 & 0 & 0 & 0 & 0 & 0 & 0 & 0 & 0 & $\mathrm{~V}_{14}$ \\
0 & 0 & 0 & 0 & 0 & 0 & 0 & 0 & 0 & 0 & 0 & 0 & 0 & 0 & 0 & $\mathrm{~V}_{15}$ \\
\hline
\end{tabular}

From $\mathrm{A}^{3}$, we notice that there is only one path of length 3 from $\mathrm{V}_{1}$ to $\mathrm{V}_{9}$ and from the graph it is $\mathrm{B} \longrightarrow \mathrm{COF} \longrightarrow \mathrm{M} \longrightarrow \mathrm{BT}$. Furthermore, we compute $\mathrm{A}^{4}$.

\begin{tabular}{|c|c|c|c|c|c|c|c|c|c|c|c|c|c|c|c|c|}
\hline & $V_{1}$ & $V_{2}$ & $V_{3}$ & $V_{4}$ & $V_{5}$ & $V_{6}$ & $V_{7}$ & $V_{8}$ & $V_{9}$ & $V_{10}$ & $V_{11}$ & $V_{12}$ & $V_{13}$ & $V_{14}$ & $V_{15}$ & \\
\hline \multirow{15}{*}{$\mathrm{A}^{4}=$} & 0 & 0 & 0 & 0 & 0 & 0 & 0 & 0 & 1 & 0 & 0 & 0 & 0 & 0 & 0 & $\mathrm{~V}_{\mathrm{l}}$ \\
\hline & 0 & 0 & 0 & 0 & 0 & 0 & 0 & 0 & 0 & 0 & 0 & 0 & 0 & 0 & 0 & $\mathrm{~V}_{2}$ \\
\hline & 0 & 0 & 1 & 0 & 0 & 0 & 0 & 0 & 0 & 0 & 0 & 0 & 0 & 0 & 0 & $\mathrm{~V}_{3}$ \\
\hline & 0 & 0 & 0 & 0 & 0 & 0 & 0 & 0 & 1 & 0 & 0 & 0 & 0 & 0 & 0 & $\mathrm{~V}_{4}$ \\
\hline & 0 & 0 & 0 & 0 & 0 & 0 & 0 & 0 & 0 & 0 & 0 & 0 & 0 & 0 & 0 & $\mathrm{~V}_{5}$ \\
\hline & 0 & 0 & 0 & 0 & 0 & 0 & 0 & 0 & 0 & 0 & 0 & 0 & 0 & 0 & 0 & $\mathrm{~V}_{6}$ \\
\hline & 0 & 0 & 0 & 0 & 0 & 0 & 0 & 0 & 0 & 0 & 0 & 0 & 0 & 0 & 0 & $V_{7}$ \\
\hline & 0 & 0 & 0 & 0 & 0 & 0 & 0 & 0 & 0 & 0 & 0 & 0 & 0 & 0 & 0 & $\mathrm{~V}_{8}$ \\
\hline & 0 & 0 & 0 & 0 & 0 & 0 & 0 & 0 & 0 & 0 & 0 & 0 & 0 & 0 & 0 & $V_{9}$ \\
\hline & 0 & 0 & 0 & 0 & 0 & 0 & 0 & 0 & 0 & 0 & 0 & 0 & 0 & 0 & 0 & $\mathrm{~V}_{10}$ \\
\hline & 0 & 0 & 0 & 0 & 0 & 0 & 0 & 0 & 0 & 0 & 0 & 0 & 0 & 0 & 0 & $\mathrm{~V}_{11}$ \\
\hline & 0 & 0 & 0 & 0 & 0 & 0 & 0 & 0 & 0 & 0 & 0 & 0 & 0 & 0 & 0 & $V_{12}$ \\
\hline & 0 & 0 & 0 & 0 & 0 & 0 & 0 & 0 & 0 & 0 & 0 & 0 & 0 & 0 & 0 & $V_{13}$ \\
\hline & 0 & 0 & 0 & 0 & 0 & 0 & 0 & 0 & 0 & 0 & 0 & 0 & 0 & 0 & 0 & $V_{14}$ \\
\hline & 0 & 0 & 0 & 0 & 0 & 0 & 0 & 0 & 0 & 0 & 0 & 0 & 0 & 0 & 0 & $\mathrm{~V}_{15}$ \\
\hline
\end{tabular}

From $\mathrm{A}^{4}$, we notice that there are no paths of length four from $V_{1}$ to $V_{15}$ but there exists only one path of length four from $\mathrm{V}_{1}$ to $\mathrm{V}_{9}$ and from the graph we have it to be $\mathrm{B} \rightarrow$ $\mathrm{BOM} \rightarrow \mathrm{COF} \rightarrow \mathrm{M} \rightarrow \mathrm{BT}$. The matrices $\mathrm{A}^{3}$ and $\mathrm{A}^{4}$ both satisfy the above theorem as well.

5. The in-degree of a vertex $\mathrm{V}$ denoted by $\operatorname{Deg}^{-}(\mathrm{V})$ is the number of edges with $\mathrm{V}$ as terminal vertex and the out-degree of a vertex denoted by $\operatorname{Deg}^{+}(\mathrm{V})$ is the number of edges with $\mathrm{V}$ as initial vertex.

From the graph, the in-degree of vertices are given to be
$\operatorname{Deg}^{-}\left(\mathrm{V}_{1}\right)=0$
$\operatorname{Deg}^{-}\left(\mathrm{V}_{6}\right)=1$
$\operatorname{Deg}\left(\mathrm{V}_{10}\right)=1$
$\operatorname{Deg}^{-}\left(\mathrm{V}_{2}\right)=1$
$\operatorname{Deg}^{-}\left(\mathrm{V}_{7}\right)=1$
$\operatorname{Deg}^{-}\left(\mathrm{V}_{12}\right)=1$
$\operatorname{Deg}^{-}\left(\mathrm{V}_{3}\right)=2$
$\operatorname{Deg}^{-}\left(\mathrm{V}_{8}\right)=1$
$\operatorname{Deg}^{-}\left(\mathrm{V}_{13}\right)=1$
$\operatorname{Deg}^{-}\left(\mathrm{V}_{4}\right)=0$
$\operatorname{Deg}^{-}\left(\mathrm{V}_{9}\right)=1$
$\operatorname{Deg}^{-}\left(\mathrm{V}_{14}\right)=1$
$\operatorname{Deg}^{-}\left(V_{5}\right)=1$
$\operatorname{Deg}^{-}\left(\mathrm{V}_{15}\right)=1$

The total of the in-degree is 14 .

The out degrees of the vertices are

$\operatorname{Deg}^{+}\left(V_{1}\right)=5$

$\operatorname{Deg}^{+}\left(V_{9}\right)=0$
$\operatorname{Deg}^{+}\left(V_{2}\right)=1$
$\operatorname{Deg}^{+}\left(\mathrm{V}_{10}\right)=1$
$\operatorname{Deg}^{+}\left(V_{3}\right)=4$
$\operatorname{Deg}^{+}\left(V_{11}\right)=1$
$\operatorname{Deg}^{+}\left(V_{4}\right)=0$
$\operatorname{Deg}^{+}\left(V_{12}\right)=1$
$\operatorname{Deg}^{+}\left(V_{5}\right)=0$
$\operatorname{Deg}^{+}\left(V_{13}\right)=0$
$\operatorname{Deg}^{+}\left(\mathrm{V}_{6}\right)=1$
$\operatorname{Deg}^{+}\left(V_{14}\right)=0$
$\operatorname{Deg}^{+}\left(V_{7}\right)=0$
$\operatorname{Deg}^{+}\left(V_{15}\right)=0$
$\operatorname{Deg}^{+}\left(V_{8}\right)=0$

The sum of out degree of the vertices is 14.This satisfies the theorem that let $\mathrm{G}$ be a graph with directed edges, then the sum of the in-degree of the vertices equals the sum of the out-degree of the vertices. i.e.

$$
\frac{\Sigma \operatorname{deg}^{-}(V)}{v \varepsilon V}=\frac{\Sigma \operatorname{deg}^{+}(V)}{v \varepsilon V}
$$

\subsubsection{Oueuing Process at Intercontinental Bank Plc}

The bank is the number one employer of people in the country. The 25 banks in the country account for over $30 \%$ of the working population. From the information obtained 
from the bank, it was observed that a branch of intercontinental plc operates with 3 relationship managers who have about 4 relationship officers each reporting to them thus making a total of 15 marketing staff. The branch also runs with one branch operations manager, one branch manager and one cash officer. The branch head oversees the bank's daily activities. The branch operations manager oversees all the operations activities i.e. cash withdrawals deposits and cheque confirmations and authorizations. The cash officer oversees all the cash transactions done by the tellers.

The following observations were made;

1. The relationship officers have the same authorization and thus can report to one relationship manager without compromising the bank's activities.

2. The branch operations manager can function in the capacity of the cash officer if her time is properly managed.

3. The branch runs with 4 teller, 2 customer service officers, 4 bulk tellers, 2 fund transfer officers and a Branch resident controller all in the operations unit. Due to introduction of Automated Teller machines i.e. ATM capable of dispensing money to customers, it was observed that at some point, one or more tellers will have no customer to attend to. Also note that the fund transfer officer, merchant tellers and Front tellers have the same posting rights i.e. can send customers money and also withdraw from the system.

\section{Deductions from the Observations}

1. Since all the 12 relationship officers can report to one manager without compromising the activities of the bank the remaining two Relationship managers become excesses.

2. As a result of the branch operations manager being able to function both in his capacity and that of the cash officer comfortably with proper time management, the cash officer becomes an excess.

3. As a result of the introduction of the Automated teller machines, some of the tellers who have no customers to serve at some point become excesses.

It is well noted that every organization wants to make more profit and reduce operations cost to the barest minimum. It is not surprising that the banks also seek a way to minimize cost of running their activities. The bank can make more money by reducing the excess staff it has but before we go ahead to, there are some certain major factors to be put into considerations when carrying out a reduction in the number of staff working in a branch of intercontinental bank plc.

1. Traffic intensity of the bank i.e. how many customers come into the bank at a particular time.

2. Service rendered at each time and the speed in which these services are being rendered.

Taking the above factors into consideration, we thus apply theory of queues to be able to achieve a proper reduction. Please note that a queue is simply a waiting line.

\subsection{Characteristic Features of a Queuing System}

\subsubsection{The Arrival Pattern}

This specifies the customers rate of arrival and the statistical pattern in which the customers arrive .Another way of looking at the arrival pattern is to consider the statistical pattern of inter-arrival time which is the length of the time between two successive arrivals.

\subsubsection{The Service Mechanism}

- This specifies the service time, the capacity of the service system and the availability of service.

- The service time is the length of time used in serving a customer. It is often given by a statistical distribution.

- The capacity of the service system has to do with the maximum number of customers that can be served at that time.

- The availability of service refers to when service can be rendered together with any restrictions placed on them.

\subsubsection{The Queue Discipline}

- This specifies the order in which the customers are served. Examples of queue discipline are,

a) First come first served (FCFS)

b) Last come, first served (LCFS)

c) Priority or preferential queue discipline.

d) Serve in random order (SIRO)

\subsubsection{Measurement of Queues}

The strength of a queue can be measured by considering three factors as follows,

i. The length of the queue.

ii. The waiting time per customer on the queue

iii. The busy period of the queuing system.

\subsubsection{The Length of the Queue}

This specifies the number of customers that can be found on the queue at any give time $t$. It includes the number of customers being severed (if any) at that time.

\subsubsection{Waiting Time}

The waiting time of a customer is defined to include both the time he spends on the queue and the time used in serving him. It is the sum of his queuing time and his service time.

\subsubsection{Busy Period}

A busy period in the system is defined to begin whenever a customer arrives to find the server free to serve him immediately and ends when next the server is free. The duration of the busy period is called its length.

\subsubsection{Mathematical Analysis}

The analysis and data used are based on the staff strength, customer inflow and the rate at which customers depart from the bank after being served. It was observed that from the time the branch opens for business, they are usually about 80 customers who need some services walking into the bank in every 10 minutes. Out of these customers, 44 
want to withdraw money or get their cheques confirmed and will have to meet one of the front tellers who are 4 in number, 20 of the customers want to pay money into an account and will have to meet anyone of the 4 bulk tellers, 11 customers want to check their account balance, confirm a cheque or open an account and will have to meet anyone of the customer service officers. The remaining 5 customers want to do a cash transfer and will go to the funds transfer officer's desk. The bank is an example of an MIMIC queue i.e. a c-server queue with Poisson distribution of arrivals and exponential service time with $\mathrm{C}$ number of parallel channels. Please note that by Poisson distribution of arrivals we mean the following;

1. The numbers of events occurring in two disjoint intervals of time are independent.

2. The probability of simultaneous occurrence of 2 or more events during a time interval is $\mathrm{O}(\mathrm{h})$ i.e. order of $h$.

3. The probability that at least one event occurs in a time period $h$ is a function $h$.

Also note that in this analysis, all factors affecting normal banking operations example power failure and system server failure are considered to be non-existent.

The table below gives a distribution of customers to the staff as they arrive into the bank and the number of customer leaving each staff after being attended to. Please note that the 4 tellers will be named teller A, teller B, teller $\mathrm{C}$, teller D. The customer service officers will be named customer service officer A and customer service officer B. The 4 bulk tellers will be bulk teller A, bulk teller B, bulk teller $\mathrm{C}$ and bulk teller $\mathrm{D}$ while the 2 funds transfer officers will be fund transfer officer $\mathrm{A}$ and funds transfer officer $\mathrm{B}$.

Table 1: Distribution of Customers to the Staff on the Arrival and Departure Rate

\begin{tabular}{lccc}
\hline $\begin{array}{l}\text { Staff } \\
\text { Designation }\end{array}$ & Staff & $\begin{array}{c}\text { Arrival rate of } \\
\text { customer per 10 } \\
\text { minutes }\end{array}$ & $\begin{array}{c}\text { Departure rate of } \\
\text { customers per 10 } \\
\text { minutes }\end{array}$ \\
\hline Teller & Teller A & 9 & 16 \\
& $\begin{array}{l}\text { Teller B } \\
\text { Teller C }\end{array}$ & 10 & 25 \\
& Teller D & 11 & 21 \\
Customer & C.S.O.A & 7 & 22 \\
service officer & C.S.O.B & 4 & 17 \\
i.e. C.S.0 & & & 16 \\
& B.T.A & 6 & 13 \\
Bulk Teller i.e. & B.T.B & 4 & 11 \\
B.T & B.T.C & 7 & 12 \\
& B.T.D & 3 & 14 \\
Funds Transfer & F.T.A & 4 & 13 \\
i.e. F.T & F.T.B & 1 & 11 \\
\hline
\end{tabular}

For the mathematical analysis of data, we will be making use of the following formulas;

1. Traffic intensity $(\ell)=\lambda / \mu$ where $\lambda$ is the mean rate of arrivals of customers per unit time $\mu$ is the mean rate of departures of customers per unit time.
2. Expected number of people in the system $\left(\mathrm{L}_{\mathrm{s}}\right)=\ell / 1-\ell$. Please note the system here involves both the people on the queue and the people being attended to by the server.

3. Expected number of people in the queue $\left(\mathrm{L}_{\mathrm{q}}\right)=\ell \mathrm{Ls}$.

4. Mean waiting time in the system $\left(\mathrm{W}_{\mathrm{s}}\right)=1 / \lambda \mathrm{Ls}$.

5. Mean waiting time in the queue $\left(\mathrm{W}_{\mathrm{q}}\right)=1 / \lambda \mathrm{L}_{\mathrm{q}}$. With the above formulas using the data obtained from the bank, we perform the necessary calculations to get the data required for each member of staff as follows

\section{Teller $A$}

Mean arrival of customer $(\lambda)-9$ customers in 10 minutes $=>\mu=9 / 10$.

Mean rate of departures of customers $(\mu)=16$ customers in 10 minutes. $=>\mu=16 / 10$.

Traffic intensity $(\ell)=\lambda / \mu=>9 / 10 \times 10 / 16=9 / 16$.

Expected number of people in the system $\left(\mathrm{L}_{\mathrm{s}}\right)=\ell / 1-\ell=$ $9 / 16 \times 16 / 7=9 / 7$

Expected number of people in the queue $\left(\mathrm{L}_{\mathrm{q}}\right)=\ell \mathrm{L}_{\mathrm{s}}=$ $9 / 16 \times 9 / 7=81 / 112$ people.

Mean waiting time in the system $\left(\mathrm{W}_{\mathrm{q}}\right)=1 / \lambda \mathrm{L}=10 / 9 \times$ $81 / 112=45 / 56$ minutes.

Mean waiting time in queue $\left(\mathrm{W}_{\mathrm{q}}\right)=1 / \lambda \mathrm{L}_{\mathrm{q}}$

\section{Teller B}

Mean arrival of customer $(\lambda)=10$ customers in 10 minutes $=>\lambda=1$

Mean rate of departures of customers $(\mu)=25$ customers in 10 minutes $=>\mu=25 / 10$

Traffic intensity $(\ell)=10 / 25$

Expected number of people in the system $\left(\mathrm{L}_{\mathrm{s}}\right)=2 / 3$ people.

Expected number of people in the system $\left(\mathrm{L}_{\mathrm{q}}\right)=1 / 15$ people

Mean waiting time in the system $\left(\mathrm{W}_{\mathrm{s}}\right)=1 / \lambda \mathrm{Ls}=2 / 3$ minutes

Mean waiting time in the queue $\left(\mathrm{W}_{\mathrm{q}}\right)=4 / 15$ minutes.

\section{Teller C}

Mean arrival of customers $(\lambda)=11 / 10$.

Mean rate of departures $(\mu)=21 / 10$

Traffic intensity $(\ell)=11 / 21$

Expected number of people in the system $\left(\mathrm{L}_{\mathrm{s}}\right)=11 / 10$ people

Expected number of people in the queue $\left(\mathrm{L}_{\mathrm{q}}\right)=121 / 210$ people

Mean waiting time in the system $\left(\mathrm{W}_{\mathrm{s}}\right)=1$ minute

Mean waiting time in the queue $\left(\mathrm{W}_{\mathrm{q}}\right)=11 / 21$ minutes

\section{Teller D}

Mean arrival of customers $(\lambda)=14 / 10$

Mean rates of departures $(\mu)=2 / 10$

Traffic intensity $(\ell)=7 / 11$

Expected number of people in the system $\left(\mathrm{L}_{\mathrm{s}}\right)=7 / 4$ people

Expected number of people in the system $(\mathrm{L})=49 / 44$ people. 
Mean waiting time in the system $\left(\mathrm{W}_{\mathrm{s}}\right)=5 / 4$ minutes.

Mean waiting time in the queue $\left(\mathrm{W}_{\mathrm{q}}\right)=35 / 44$ minutes

\subsubsection{Deductions from Calculation}

Notice from our calculations that;

1. At some point in time, teller B will have no one in his queue to serve.

2. Teller $\mathrm{D}$ has the highest traffic intensity i.e. more people were served by teller D.

\section{Customer Service Officer's Desk}

Customer Service Officer $\lambda$.

Mean arrival of customers $(\lambda)=7$ customers in 10 minutes $=7 / 10$.

Mean rate of departures of customers $(\mu)=17 / 10$

Traffic intensity $(\ell)=7 / 17$

Expected number of people in the system $\left(\mathrm{L}_{\mathrm{s}}\right)=7 / 10$ people

Expected number of people in the queue $\left(\mathrm{L}_{\mathrm{q}}\right)=49 / 170$ people

Mean waiting time in the system $\left(\mathrm{W}_{\mathrm{s}}\right)=1$ minute

Mean waiting time in the queue $\left(\mathrm{W}_{\mathrm{q}}\right)=7 / 17$ minutes

Customer Service Officer B

Mean arrival of customers $(\lambda)=4 / 10$

Mean rate of departures of customers $(\mu)=16 / 10$

Traffic intensity $(\ell)=1 / 4$

Expected number of people in the system $\left(\mathrm{L}_{\mathrm{s}}\right)=1 / 3$ people

Expected number of people in the queue $\left(\mathrm{L}_{\mathrm{q}}\right)=1 / 12$ people.

Mean waiting time in the system $\left(\mathrm{W}_{\mathrm{s}}\right)=1 / 6$ minutes.

Mean waiting time in the queue $\left(\mathrm{W}_{\mathrm{q}}\right)=5 / 24$ minutes.

\section{Deductions from Calculation}

1. Customer service officer A has more customers on the queue than customer service officer B.

2. A person served by customer service officer A will spend more time than the person served by customer service officer B.

\section{Bulk Tellers}

\section{Bulk Teller A} $6 / 10$

Mean arrival of customers $(\lambda)=6$ in 10 minutes $=>\lambda=$

Mean rate of departures of customers $(\mu)=13 / 10$

Traffic intensity $(\ell)=6 / 13$

Expected number of people in the system $\left(\mathrm{L}_{\mathrm{s}}\right)=6 / 7$ people.

Expected number of people on the queue $\left(\mathrm{L}_{\mathrm{q}}\right)-36 / 91$ people.

Mean waiting time in the system $=\left(\mathrm{W}_{\mathrm{s}}\right)=10 / 7$ minutes

Mean waiting time in the queue $\left(\mathrm{W}_{\mathrm{q}}\right)=60 / 91$ minutes.

\section{Bulk Teller B}

Mean arrival of customer $(\lambda)=4 / 10$

Mean rate of departures of customers $(\mu)=11 / 10$

Traffic intensity $(\ell)=4 / 11$

Expected number of people in the system $\left(L_{s}\right)=4 / 7$ people

Expected number of people in the queue $\left(\mathrm{L}_{\mathrm{q}}\right)=16 / 77$ people

Mean waiting time in the system $\left(\mathrm{W}_{\mathrm{s}}\right)=10 / 7$ minutes.

Mean waiting time in the queue $\left(\mathrm{W}_{\mathrm{q}}\right)=40 / 77$ minutes

\section{Bulk Teller C}

Mean arrival of customer $(\lambda)=7 / 10$.

Mean rate of departures of customers $(\mu)=12 / 10$

Traffic intensity $(\ell)=7 / 12$

Expected number of people in the system $(\mathrm{L})=7 / 5$ people

Expected number of people in the queue $\left(\mathrm{L}_{\mathrm{q}}\right)=49 / 60$ people

Mean waiting time of customers in the system $\left(\mathrm{W}_{\mathrm{s}}\right)=2$ minutes

Mean waiting time of customers in the queue $\left(\mathrm{W}_{\mathrm{q}}\right)=7 / 6$ minutes

\section{Bulk teller D}

Mean arrival of customers $(\lambda)=3 / 10$.

Mean rate of departures of customers $(\mu)=14 / 10$

Traffic intensity $(\ell)=3 / 14$

Expected number of people in the system $\left(\mathrm{L}_{\mathrm{s}}\right)=3 / 11$ people

Expected number of people in the queue $\left(\mathrm{L}_{\mathrm{q}}\right)=\frac{9}{154}$ people

Mean waiting time in the system $\left(\mathrm{W}_{\mathrm{s}}\right)=10 / 11$ minutes

Mean waiting time in the queue $\left(\mathrm{W}_{\mathrm{q}}\right)=15 / 77$ minutes

\section{Deductions from Calculations}

Notice from our calculations that:

1. At some point in time. Bulk teller Band D will have no one in their queues to serve.

2. A person served by teller $\mathrm{C}$ will spend more time in the queue than any other teller.

3. Teller $\mathrm{C}$ has the highest traffic intensity i.e. more people were served by bulk teller C.

\section{Funds Transfer}

\section{Funds Transfer $A$}

Mean arrival of customers $(\lambda)=4 / 10$

Mean rate of departures of customers $(\mu)=13 / 10$.

Traffic intensity $(\ell)=4 / 13$.

Expected number of people in the system $\left(\mathrm{L}_{\mathrm{s}}\right)=4 / 9$ people

Expected number of customers in the system $\left(\mathrm{W}_{\mathrm{s}}\right)=10 / 9$ minutes.

Mean waiting time in the system $\left(\mathrm{W}_{\mathrm{s}}\right)=10 / 9$ minutes

Mean waiting time of customers in the queue $\left(\mathrm{W}_{\mathrm{q}}\right)=$ 40/117 minutes.

\section{Funds Transfer B}

Mean arrival of customers $(\lambda)=1 / 10$

Mean rate of departures of customer $(\mu)=11 / 10$.

Traffic1ntensity $(\ell)=1 / 11$

Expected number of people in the system $\left(L_{s}\right)=1 / 10$ 
Expected number of people in the queue $\left(\mathrm{L}_{\mathrm{q}}\right)=1 / 110$ people. This means that there is approximately no one in the queue.

Mean waiting time in the system $\left(\mathrm{W}_{\mathrm{s}}\right)=1$ minute

Mean waiting time in the queue $\left(\mathrm{W}_{\mathrm{q}}\right)=1 / 11$ minutes

\section{Findings}

A customer served by funds transfer A will spend more time on the queue than a customer served by funds transfer B. Based on the deductions from the calculations; we can get a modification on the staff strength by dropping some of the less efficient staff. To do this effectively, we put into consideration the various time spent on the queue by the customers while waiting to be attended to by the server. When a customer spends less time on the queue of a particular sever, it simply means that the server is efficient and very fast in attending to customers but if a customer spends-more time on the queue while waiting to be attended to, it means that the server is less efficient. Below is the modified table of the staff strength after reduction. In the table, the most efficient staff were retained while the least efficient ones were dropped. Also note that the traffic flow however was still maintained. We are interested in knowing if there will be an overcrowding in the banking hall or if there will be a reduction in the number of customers in the banking hall if the reductions in the staff strength are made.

Table 2: Modified Table after Staff Reduction

\begin{tabular}{|c|c|c|c|}
\hline $\begin{array}{l}\text { Staff } \\
\text { designation }\end{array}$ & Particular staff & $\begin{array}{c}\text { Arrival rat of } \\
\text { customers per } \\
10 \text { minutes }\end{array}$ & $\begin{array}{c}\text { Departure rate } \\
\text { of customers } \\
\text { per } 10 \text { minutes }\end{array}$ \\
\hline \multirow{2}{*}{ Teller } & Teller C & 20 & 21 \\
\hline & Teller D & 24 & 22 \\
\hline $\begin{array}{l}\text { Customer } \\
\text { service } \\
\text { (C.S) }\end{array}$ & $\begin{array}{c}\text { Customer } \\
\text { service officer } \\
\text { B }\end{array}$ & 11 & 16 \\
\hline Bulk teller & $\begin{array}{l}\text { Bulk teller A } \\
\text { Bulk teller D }\end{array}$ & $\begin{array}{l}10 \\
10\end{array}$ & $\begin{array}{l}11 \\
12\end{array}$ \\
\hline $\begin{array}{l}\text { Funds } \\
\text { transfer }\end{array}$ & $\begin{array}{c}\text { Funds transfer } \\
\text { B }\end{array}$ & 5 & 11 \\
\hline
\end{tabular}

To carryout the mathematical analysis of this data, we will be making use of the same formulas. See from the modified table that the numbers of customers arriving into the bank still remain the same as they were with the original staff strength ie the staff strength before the reduction.

\section{Front Tellers}

\section{Teller C}

Mean arrival of customers $(\lambda)=20$ customers in 10 minutes $=20 / 10$.

Mean rate of departures of customers $(\mu)=21$ customers in 10 minutes.

Traffic intensity $(\ell)=20 / 21$

Expected number of people in the system $\left(\mathrm{L}_{\mathrm{s}}\right)=20$ people. 21

Expected number of people in the time $\left(\mathrm{L}_{\mathrm{q}}\right)=400$ people

Mean waiting time in the system $\left(\mathrm{W}_{\mathrm{s}}\right)=10$ minutes

Mean waiting time in the queue $\left(\mathrm{W}_{\mathrm{q}}\right)=200 / 21$ minutes

\section{Teller D}

Mean arrival of customers $(\lambda)=20$ customers in 10 minutes

$\lambda=20 / 10$

Mean rate of departures of customers $(\mu)=21 / 10$

Traffic intensity $(\ell)=20 / 21$

Expected number of people in the system $\left(\mathrm{L}_{\mathrm{s}}\right)=20$ people

Expected number of people in the queue $\left(\mathrm{L}_{\mathrm{q}}\right)=$ $\frac{400}{21}$ people

Mean waiting time in the system $\left(\mathrm{W}_{\mathrm{s}}\right)=10$ minutes

Mean waiting time in the queue $\left(\mathrm{W}_{\mathrm{q}}\right)=\frac{200}{21}$ minutes

\section{Customer Service}

\section{Customer Service Officer B}

Mean arrival of customers $(\lambda)$ - 11 customers 10 minutes $=\lambda=11 / 10$.

Mean rate of departures of customers $(\mu)=16 / 10$

Traffic intensity $(\ell)=11 / 16$.

Expected number of people in the system $\left(\mathrm{L}_{\mathrm{s}}\right)=11 / 5$ people

Expected number of people in the queue $\left(\mathrm{L}_{\mathrm{q}}\right)=\frac{121}{80}$ people

Mean waiting time in the system $\left(\mathrm{W}_{\mathrm{s}}\right)=2$ minutes

Mean waiting time in the queue $\left(\mathrm{W}_{\mathrm{q}}\right)=11 / 8$ minutes

\section{Bulk Tellers}

\section{Bulk Teller $A$}

Mean arrival of customers $(\lambda)=10$ customers in 10 minutes $=>\lambda=1$

Mean rate of departures of customers $(\mu)=11$ customers in

10 minutes $=>\mu=11 / 10$

Traffic intensity $(\ell)=10 / 11$.

Expected number of people in the system $\left(\mathrm{L}_{\mathrm{s}}\right)=1 / 10$ people

Expected number of people in the queue $\left(\mathrm{L}_{\mathrm{q}}\right)=10 / 121$ people.

Mean waiting time in the system $\left(\mathrm{W}_{\mathrm{s}}\right)=1 / 11$ minutes

Mean waiting time in the queue $\left(\mathrm{W}_{\mathrm{q}}\right)=10 / 121$ minutes

\section{Bulk teller D}

Mean arrival of customers $(\lambda)=10$ customers in 10 minutes $=>\lambda=1$ 

in

Mean rate of departures of customers $(\mu)=12$ customers

10 minutes $=>\lambda / \mu=12 / 10$

Traffic intensity $(\ell)=10 / 12$

Expected number of people in the system $\left(\mathrm{L}_{\mathrm{s}}\right)=5$ people.

Expected number of people in the queue $\left(\mathrm{L}_{\mathrm{q}}\right)=\frac{50}{12}$ people

Mean waiting time in the system $\left(\mathrm{W}_{\mathrm{s}}\right)=5$ minutes

Mean waiting time in the queue $\left(\mathrm{W}_{\mathrm{q}}\right)=50 / 12$ minutes

\section{Funds Transfer}

\section{Funds Transfer of Server B}

Mean arrival of customers $(\lambda)=5$ customers in 10 minutes $\Rightarrow \lambda=1 / 2$

Mean rate of departures of customer $(\mu)-11$ customers in

10 minutes $=>\mu=11 / 10$

Traffic intensity $(\ell)=\lambda / \mu=10 / 22$.

Expected intensity of people in the system $\left(\mathrm{L}_{\mathrm{s}}\right)=5 / 6$ people

Expected number of people in the queue $\left(\mathrm{L}_{\mathrm{q}}\right)=\frac{25}{66}$ people

Mean waiting time in the system $\left(\mathrm{W}_{\mathrm{s}}\right)=5 / 3$ minutes

Mean waiting time in the queue $\left(\mathrm{W}_{\mathrm{m}}\right)=25$ minutes

\subsection{Analysis of Result}

We notice from the calculations that;

1. From the front teller's desk, both tellers will have at least 20 people on their various queues to serve at any point in time. Also notice that there is an increase in the waiting time of the customers i.e. the time it takes to serve a customer. This can be reduced by the introduction of ATM i.e. automated Teller machines which can dispense money to customers. With the use of ATMS, the crowd in the banking hall will be reduced and there will be fewer customers for the tellers to attend to. This will bring about a reduction in the waiting time of the customers.

2. The customer's service desk will have more customers on the queue but this is not enough to be termed overcrowding. This means that one customer service officer can serve the branch.

3. Bulk tellers A and D can comfortably handle the branch without compromising the bank's daily activities.

The funds transfer officer can handle his duties without problem. The bank can make more profit by reducing its number of staff without compromising its activities.

\subsection{Tabulation of Results}

Table 3: Tabulation of Results before Staff Reduction

\begin{tabular}{|c|c|c|c|c|c|c|}
\hline $\begin{array}{l}\text { sections of } \\
\text { operations unit }\end{array}$ & $\begin{array}{l}\text { Particular } \\
\text { staff }\end{array}$ & $\begin{array}{l}\text { Traffic } \\
\text { intensity }\end{array}$ & $\begin{array}{l}\text { Expected number of } \\
\text { people in the system in } \\
10 \text { minutes(Ls) }\end{array}$ & $\begin{array}{l}\text { Expected number of } \\
\text { people in the queue in } \\
10 \mathrm{mins}(\mathrm{lq})\end{array}$ & $\begin{array}{l}\text { Mean waiting } \\
\text { time in the system } \\
\text { Ws minutes }\end{array}$ & $\begin{array}{l}\text { Mean waiting } \\
\text { time in the queue } \\
\text { Wq minutes }\end{array}$ \\
\hline \multirow{4}{*}{ Front tellers } & Teller A & $9 / 16$ & $9 / 7$ & $81 / 112$ & $10 / 7$ & $45 / 56$ \\
\hline & Teller B & $10 / 25$ & $2 / 3$ & $4 / 15$ & $2 / 3$ & $4 / 15$ \\
\hline & Teller C & $11 / 21$ & $11 / 10$ & $121 / 210$ & 1 & $11 / 21$ \\
\hline & Teller D & $7 / 11$ & $7 / 4$ & $49 / 44$ & $5 / 4$ & $35 / 44$ \\
\hline \multirow{2}{*}{$\begin{array}{l}\text { Costumer care } \\
\text { officers }\end{array}$} & C.S.O.A & $7 / 17$ & $7 / 10$ & $49 / 170$ & 1 & $7 / 17$ \\
\hline & C.S.O.B & $1 / 4$ & $1 / 3$ & $1 / 12$ & $1 / 6$ & $5 / 24$ \\
\hline \multirow{4}{*}{ Bulk Teller (B.T) } & B.T.A & $6 / 13$ & $6 / 7$ & $36 / 91$ & $10 / 7$ & $60 / 91$ \\
\hline & B.T.B & $4 / 11$ & $4 / 7$ & $16 / 77$ & $10 / 7$ & $40 / 77$ \\
\hline & B.T.C & $7 / 12$ & $7 / 5$ & $49 / 60$ & 2 & $7 / 6$ \\
\hline & B.T.D & $3 / 14$ & $3 / 11$ & $9 / 54$ & $10 / 11$ & $15 / 77$ \\
\hline \multirow{2}{*}{$\begin{array}{l}\text { Fund transfer } \\
\text { (F.T) }\end{array}$} & F.T.A & $4 / 13$ & $4 / 9$ & $16 / 17$ & $10 / 9$ & $40 / 117$ \\
\hline & F.T.B & $1 / 11$ & $1 / 10$ & $1 / 110$ & 1 & $1 / 11$ \\
\hline
\end{tabular}

Table 4: Modified Table after Staff Reduction

\begin{tabular}{|c|c|c|c|c|c|c|}
\hline $\begin{array}{l}\text { Section of } \\
\text { the unit }\end{array}$ & $\begin{array}{l}\text { Particular } \\
\text { staff }\end{array}$ & $\begin{array}{l}\text { Traffic } \\
\text { intensity }(\ell)\end{array}$ & $\begin{array}{l}\text { Expected number of } \\
\text { people in the system } \\
\text { in } 10 \text { minutes } \mathrm{Ls} \text { ) }\end{array}$ & $\begin{array}{l}\text { Expected number of } \\
\text { people in the queue } \\
\text { in } 10 \mathrm{mins}(\mathrm{Lq})\end{array}$ & $\begin{array}{l}\text { Mean waiting } \\
\text { time in the system } \\
\text { Ws minutes }\end{array}$ & $\begin{array}{l}\text { Mean waiting } \\
\text { time in the queue } \\
\text { Wq minutes }\end{array}$ \\
\hline Front & Teller C & $20 / 21$ & 20 & $400 / 21$ & 10 & $200 / 21$ \\
\hline tellers & Teller D & $20 / 21$ & 20 & $400 / 21$ & 10 & $200 / 21$ \\
\hline Costumer service & C.S.O.B & $11 / 16$ & $11 / 5$ & $121 / 80$ & 2 & $11 / 6$ \\
\hline $\begin{array}{l}\text { Funds } \\
\text { transfer }\end{array}$ & $\begin{array}{l}\text { Funds } \\
\text { transfer B }\end{array}$ & $10 / 22$ & $5 / 6$ & $25 / 66$ & $5 / 3$ & $25 / 33$ \\
\hline Bulk & B.T.A & $10 / 11$ & $1 / 10$ & $10 / 121$ & $1 / 11$ & $10 / 121$ \\
\hline Teller & B.T.O & $10 / 12$ & 5 & $50 / 12$ & 5 & $50 / 12$ \\
\hline
\end{tabular}




\section{Summary}

A reduction in the number of staff working in the bank will have the following monetary effects;

1. A relationship manager earns $\$ 8$ million per annum.

2. A front teller earns $\$ 2.9$ million per annum and with a cut on the two excess front tellers; the bank saves N5.6 million per annum.

3. A Bulk teller also earns $¥ 2.9$ million per annum, therefore a cut on the two excesses in the bank will save $\$ 5.6$ million per annum for the bank.

4. A cash officer earns $\$ 4.1$ million per annum and being an excess, the bank makes $\$ 4.1$ million per annum from him.

5. A funds transfer officer earns N3.0 million per annum and the bank makes $\$ 3.0$ million per annum from him since he is an excess.

In addition to a reduction in the number of staff working in a branch of intercontinental bank plc, the bank can also make more profit by getting involved in some capital intensive papers and other things which will not be discussed in the context of this work.

\section{Conclusion}

This paper was carried out with the aim of deducing a model to show the network relationship that exists among members of staff of intercontinental bank plc, and also to make more profit with a reduction in the staff strength. The data collected from intercontinental bank which served as a case study was utilized. The generalized model can be produced by taking the traffic flow in the bank into consideration. Although the new model can serve a branch with an inflow of 80 to 100 people in 10 minutes, the analysis can be adjusted as the number of people entering the bank in 10 minutes increase over a period of time thereby maintaining the necessary balance required for the smooth running of the branch.

\section{Recommendation}

Intercontinental bank plc should invest more funds in the following in order to improve the quality of their services;

(1) Automation of business processes: This involves making better use of computing in their business services. Online inter banking transfer of money, conversion of currencies confirmation of cheques should be made possible. Automation of business processes have the following advantages; improves efficiency of the bank, reduces cost, reduces error, improves quality of output and speed of delivery.
(2) The bank should invest more money in procuring ATMs that have the capacity of disbursing and receiving cash in addition to receiving cheques. More ATMs should be kept at strategic positions around the country as this will reduce the number of people coming into the bank.

(3) Stronger internal controls such as increasing the security with the use of ATMS and online cash transfer as this will encourage customers to make use of these services rather than visiting the bank all the time.

\section{References}

[1] Abbot, J.C (1969); sets, lattices and Boolean Algebra Boston, Allyn and Bacon Inc.

[2] Berge, C. (1971): Principles of Combinatorics New York Academic press.

[3] Birkhoff G and Bartee T.C (1970): Modern Applied Algebra New York, McGraw-Hill Book Company.

[4] Cayley Arthur (1987):Graph Theory and It's Applications, John Wiley and Sons.

[5] Colham, B. (1971): Matrices and Applications. New York, McGraw-Hili Book Company.

[6] Crisler, N, Fisher, P. and Fredrick, G. (1994): Discrete Mathematics Through Application. New York, W.H Freeman.

[7] Erlang, A K. (2009): The Guide to Computing Literature. Elsevier North-Holland, Inc New York USA.

[8] Gill, A. (1976): Applied Algebra for Computer Sciences Eaglewood cliffs, N.J Prentice-Hall Inc.

[9] Gustav Kirchhoff. (1976): Graphs and Hyper graphs. NorthHolland American Elsevier Pub. Co. New York.

[10] Harrari, F.C. (1973): Graph theory and theoretical Physics. New York, McGraw-Hill Book Company.

[11] Kirsten, W. (2001): Applied Abstract Algebra London, Joe Welsh and Sons.

[12] Kleinrock Leonard.(2006) : Fundamentals of Queuing Theory John Wiley and Sons Inc.

[13] Kirkman P Thomas and William R Hamilton (1856):Graph Theory Applications in Computer Science. New York McGraw-Hill Book Company.

[14] Liu Chung Laung (1977): Elements of Discrete Mathematics New York, McGraw-Hill Book Company.

[15] Taha, A.H. (2003): An Introduction to Operations Research7th Edition. Fayetteville, Prentice-Hall, Inc. New Jersey. 